\title{
Autism, Music, and the Therapeutic Potential of Music in Alexithymia
}

\section{Rory Allen and Pamela Heaton University of London, London, United Kingdom}

IT HAS BEEN ARGUED, IN VIEW OF THE SOCIAL evolutionary origins of music and the social deficits found in autism, that individuals with autism will be emotionally unresponsive to music. However, a recent study of high-functioning adults with autism has shown that they appear to have a range of responses to music similar to typically developing people, including the deliberate use of music for mood management. In examining why these responses appear unaffected in autism, we explore possible mechanisms for musical mood induction in listeners, hypothesizing that the simulation theory of empathy may illuminate current controversies over the nature of emotion in music. Drawing on these ideas, we put forward suggestions for using a simple associative learning process between musically induced emotions and their cognitive correlates for the clinical treatment of alexithymia, a disorder that is common in autism and characterized by an absence of cognitive insight into one's emotions.

Received October 6, 2009, accepted December 14, 2009.

Key words: autism, music, alexithymia, emotion, treatment

\section{Heterogeneity in Autism}

$\mathrm{D}$ ESPITE SIX DECADES OF RESEARCH, CONSENSUS on the developmental and neurological basis of autism has not been reached. It is, however, widely acknowledged that autism and autism spectrum disorders are extremely heterogeneous. This heterogeneity is manifested in great variability in the extent and severity of core diagnostic features as well as in intellectual and language impairments. Such heterogeneity limits the extent to which unitary treatment approaches can be adopted by educators and therapists. However, for verbal, intellectually able individuals with this disorder, the extent to which they are able to achieve their educational and professional goals may depend upon the development of appropriate therapies and educational approaches.

One possible contributing factor to this variability has been suggested by findings from a recent large-scale twin study (Happé, Ronald, \& Plomin, 2006). These results show that the triad of impairments that form current diagnostic criteria for autism in DSM-IV-TR (American Psychological Association, 2000) may be under the control of independent genetic factors, thus allowing for an even greater degree of heterogeneity than if there were a single, unitary mechanism underlying all three elements of the triad. Given these findings, and the intrinsic difficulties inherent in attempts to establish genotype/phenotype links for human behaviors, uncertainty about the causal mechanisms of autism is unsurprising. However, fundamental questions about the nature and the range of variability in the emotional and cognitive characteristics of autism have, too, still to be fully addressed. Among these challenges are those of isolating behavioral features that are truly unique to the condition. For example, while difficulties in understanding emotional cues in faces and voices in autism are well documented, similar difficulties have been observed in children and adults with Williams syndrome and Down syndrome. Indeed, many of the deficits assumed to characterize autism vary in severity within the disorder and are also observed in other, apparently unrelated genetic or neurodevelopmental disorders.

\section{Musical Cognition in Autism}

A number of authors (Huron, 2001; Levitin, 2006; Peretz, 2001) have speculated that individuals with autism are likely to be emotionally unresponsive to music; at most, they may respond to the structural complexity of music. They base this hypothesis on the proposal (see for example, Huron, 2001) that music evolved primarily for its value in promoting social bonding in early human society. Given that autism by definition involves deficits in social functioning, they conclude that individuals with this disorder will be deficient also in the appreciation of music.

In examining empirical data on autistic populations, it is necessary to bear in mind one important proviso

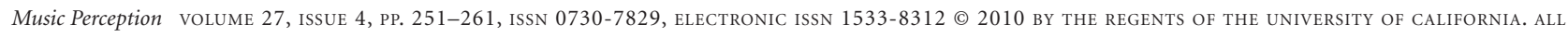
RIGHTS RESERVED. PLEASE DIRECT ALL REQUESTS FOR PERMISSION TO PHOTOCOPY OR REPRODUCE ARTICLE CONTENT THROUGH THE UNIVERSITY OF CALIFORNIA PRESS'S RIGHTS AND PERMISSIONS WEBSITE, HTTP://WWW.UCPRESSJOURNALS.COM/REPRINTINFO.ASP. DOI:10.1525/MP.2010.27.4.251 
regarding the speculation cited above. While a number of music perception and cognition in autism studies have been carried out, these have often been with samples drawn from particular sub-populations, which cannot therefore be truly representative of the wider group. For example, studies testing musical savants have described remarkable musical skills (Hermelin, O'Connor, \& Lee, 1987; Miller, 1999; Nettelbeck \& Young, 1996; Sloboda, Hermelin, \& O'Connor, 1985; Treffert, 1988; Young \& Nettlebeck, 1995). The diagnostic status of many musial savants is, however, very uncertain. While the population may include intellectually unimpaired individuals with a firm diagnosis of autism (Nettlebeck \& Young, 1996), many musical savants are visually impaired and intellectually handicapped (Miller, 1999), and unsuited to testing with standardized diagnostic instruments. Other studies investigating the existence of enhanced pitch processing in autism and its links with savant skills (e.g., Bonnel et al., 2003; Heaton, 2003; Heaton, Hermelin, \& Pring, 1998; Heaton, Pring, \& Hermelin, 1999; Mottron, Peretz, Belleville, \& Rouleau, 1999) have mostly been carried out with intellectually able individuals, and the extent to which these findings can be generalized to the wider population is unclear.

Those experimental studies that have directly tested appreciation of higher-order aspects of music in wider autism populations have focused on musical emotions. In the first of these studies, Heaton, Hermelin, and Pring (1999) showed that children with autism understood the affective connotations of musical mode sufficiently well to be able to pair schematic representations of happy and sad faces with excerpts of music in major and minor keys. In a more recent study (Heaton, Allen, Williams, Cummins, \& Happé, 2008), typically developing children, and children with Down syndrome and ASD matched musical excerpts with pictures denoting a range of affective and non-affective scenarios. Interestingly, the findings from the latter study showed that this ability was mediated by verbal mental age rather than diagnosis. However, a limitation of both of these studies is that they specifically tested the ability to make conventional musical associations, and as such, provided few insights into the nature of the participants' personal musical experiences.

Other, non-experimental investigations into the broader impact of music in autistic populations have explored the value of music in a therapeutic context. Authors sympathetic to the value of music therapy have reviewed the evidence for its effectiveness. Based on a meta-analysis of nine quantitative studies, Whipple (2004) suggested that music therapy achieves positive effects in children and adolescents with autism.
Another review by Wigram and Gold (2006) stated that there was evidence that music had notable effects in promoting interpersonal communication and relationship-building skills in children with ASD.

A question that must be addressed when considering the efficacy of music therapy in autism relates to the locus of effects. Are positive outcomes an indirect consequence of group participation or positive interactions with therapists? It has been suggested that individuals with autism are insensitive to the emotional aspects of music (Levitin, 2006), and evidence from music therapy does not in itself refute such a claim. One line of evidence that has relevance to the subject of musical responsiveness in atypical populations comes from neuroimaging work reported by Menon and Levitin (2005). This suggests that the three interconnected structures in the brain (the nucleus accumbens, ventral tegmental area, and hypothalamus) involved in the dopaminergic reward system play an important role in regulating emotional responses to music. Menon and Levitin proposed that music could therefore be used as a probe to test for anhedonia, the loss of pleasure in daily activities, in patients suffering from clinical conditions such as depression and schizophrenia. Responses to music - as an index of the integrity of the reward system-could be correlated against the severity of clinical symptoms. Given that anhedonia is not an invariable characteristic of autism, there is no reason to suppose that responsiveness to music is likely to be comprehensively damaged at this fundamental level in all individuals with this disorder. (The most recent and powerful study into neuroimaging work on reward circuit activation in music that confirms and extends the conclusions reported above, was reported by Salimpoor, Benovoy, Longo, Cooperstock, \& Zatorre, 2009).

One theory put forward to explain addictive, impulsive, or compulsive behavior, including that sometimes observed in autism, is that it results from a reduction in the number of dopamine D-2 receptors in the brain's reward circuit, which leads to dysfunctional behavioral compensation (Blum et al., 2000). The pervasive nature of the neurological effects of autism means that the presence of compulsive behaviors could well reflect a compromised reward system in some individuals. However, recent attempts to detect a genetic link between autism and defects in the reward circuit by examining the $\mathrm{NrCAM}$ gene failed to show any clear association (Sakurai et al., 2006). These data further increase the likelihood that a relatively unimpaired capacity to appreciate music will be characteristic of individuals with autism. 


\section{The Role of Music in the Lives of High-Functioning Adults with ASD}

In recent years there have been a number of studies that have focused on the complexities of how normal populations of children or adults engage with music in their everyday lives (e.g., Batt-Rawden \& DeNora, 2005, DeNora, 2002, Lamont, 2008). Some writers have suggested that the pace of technical change in the delivery of music means that it is now a resource rather than a commodity, and can be used in different situations for a variety of purposes including mood management (North, Hargreaves, \& O'Neill, 2000). These new approaches to studying the psychology of music offer a potentially fruitful way of looking at how autistic people use music in their everyday lives.

In the first study adopting this exploratory approach, Allen, Hill, and Heaton (2009) used a semi-structured questionnaire to obtain information about the musical experiences of high-functioning adults on the autism spectrum. The transcribed interviews were analyzed using NVivo7 (QSR International, 2006), a computerized aid to qualitative data analysis, employing an approach based on Grounded Theory (Glaser \& Strauss, 1967). While many high-functioning adults with ASD obtain good scores on standardized tests of language, semantic and pragmatic difficulties are nevertheless widespread in this group (e.g., Jolliffe \& Baron-Cohen, 1999). This means that direct questioning may not always be the most effective way of eliciting information. However, in some instances this approach can effectively be used with adults with highfunctioning autism or Asperger syndrome (Hill, Sally, \& Frith, 2004). While we acknowledged that conclusions drawn from such a sample may not generalize to the whole ASD population, we predicted that direct questioning could at least provide insights into the experiences of the individuals who were able to take part in our study. In fact, our participants readily responded to our questions and we learned that their uses of music were remarkably similar to those reported in the literature on typical adults and adolescents (e.g., North, Hargreaves, \& Hargreaves, 2004; North et al., 2000). These uses included self-management for depression, mood change, and social affiliation. Notable among the responses were those of individuals who acknowledged their social deficits, craved social contact, and used music to meet unfulfilled social and emotional needs, among them a sense of belonging to a wider music-loving community, or simply that of being one of a large number of people buying a particular hit record.
There was, however, one striking difference between the responses of the autistic adults who participated in our study (Allen et al., 2009) and those of the typically developing individuals reported in the literature. Those without autism describe their mood changes in response to music as lying along two axes, the first of which is 'valence,' i.e., happy/sad, and the second of which is 'arousal' (Bigand, Vieillard, Madurell, Marozeau, \& Dacquet, 2005). In contrast, the participants in our autism sample showed almost no use of valence terms, and instead used descriptors of states lying along two dimensions of arousal, with calmness/tension as opposite poles of one axis, and excitement or exhilaration as the desired state on the other axis. While they reacted to the aesthetic qualities of music, they tended to describe these as properties of the music, rather than in terms of the emotional reactions that they evoked.

This suggests similarities with a model described by Thayer (1978), which expands the traditional concept of arousal from one to two dimensions. Thayer's model can equally well be interpreted as a mood state rather than an arousal model, and we chose to look at it that way. Thayer identified dimensions of vigour/tiredness, and of tension/placidity. The latter clearly maps onto a tension/calmness dimension that emerged in the analysis of the data from the high-functioning autistic individuals who participated in our qualitative music study. Some of them described how they used music specifically to ease anxieties and reduce stress. Items from our study that corresponded to Thayer's vigour/tiredness axis included statements about the use of music to induce states of excitement or exhilaration.

The findings of Allen et al. (2009) that their ASD group described their responses to music in terms of internal arousal states rather than valence terms, is consistent with work by Capps, Yirmiya, and Sigman (1992) and Bormann-Kischkel, Vilsmeier, and Baude (1995). In these studies, autistic participants showed specific recognition impairments in response to facial emotions (e.g., embarrassment or surprise) that had an external locus of control, thereby requiring knowledge about social scripts. The findings are understandable in the light of Bowler's suggestions (2007) that "individuals with ASD seem to engage in less topdown processing when making perceptual judgements, that is to say, their reactions to the world are based on information that is closer to the properties of the incoming stimulus" (p. 246). Attributing emotional characteristics to music would seem to involve more top-down processing than describing changes in internal arousal. 
To summarize, the first scientifically rigorous studies specifically designed to investigate musical appreciation in high-functioning individuals on the autism spectrum have revealed a well developed ability to react with pleasure and appreciation to music. There is clear evidence that on the autism spectrum are sensitive to music's emotional and social dimensions. However, they do appear to experience some limitations in verbally describing their emotional experiences, and this appears to be associated with their more generalized communication difficulties.

\section{Autism and Alexithymia}

The unusual way in which high-functioning adults with autism described their affective reactions to music (Allen et al., 2009) indicates the presence of the phenomenon of alexithymia. Alexithymia, or being "without words for emotions," implicates a cluster of cognitive and affective components in a specific type of emotional dysregulation. Central to alexithymia are difficulties in identifying and describing feelings and difficulties in distinguishing feelings from the bodily sensations of emotional arousal (Hill, Berthoz, \& Frith, 2004).

Alexithymia is a common condition in ASD, possibly affecting as many as $85 \%$ of individuals (Hill, Berthoz, \& Frith, 2004). It should be noted however that alexithymia is common in a range of other disorders, including post-traumatic stress disorder (PTSD), anorexia, bulimia, major depressive disorder, and panic disorder, as well as among substance abusers. Two variants of alexithymia have been described with admirable parsimony as types I and II (Bailey \& Henry, 2007). Individuals with type I fail to experience or describe emotions, whereas those with type II show a normal or high degree of conscious awareness of emotions but a reduced capacity to cognitively appraise them. In other words, the person with type II alexithymia may experience a relatively normal range of emotions, but will have a deficit in the ability to label or identify them or discriminate between their own internal emotional states. This latter type of alexithymia is the one most commonly observed in ASD (Berthoz \& Hill, 2005).

Research comparing ASD and typical participants has shown that higher levels of alexithymia are associated with higher levels of depression in ASD. It is known that depression and alexithymia are correlated in the general population, though to date, group sizes have been too small to show such an effect within an ASD sample (Berthoz \& Hill, 2005). However, it is plausible to suggest that there may be a causal link from alexithymia to depression and anxiety, given that sufferers are confused by the nature of their negative internal feelings, and are therefore unable to identify their causes. A second related characteristic of alexithymia is that sufferers are unable to regulate their emotions. The philosopher Spinoza believed that "an emotion which is a passion ceases to be a passion as soon as we form a clear and distinct idea of it" (as cited in Russell, 1961, p. 557). The processes of naming emotions enables the individual to attribute a cause to the feelings he or she is experiencing. For Spinoza, unlabelled passions are both negative and destructive, and this labelling process diminishes the power of our passions to do us harm.

To the extent that a person's internal emotional state influences their behavior in social situations, alexithymia also can contribute to the core deficits in social functioning that are characteristic of ASD. This is because an inability to identify one's own mood state means that one cannot make allowances for the effect of this internal state on one's behavior towards others. Moreover, even if in some cases people with autism retain some sensitivity to social situations and can respond to them with appropriate changes of mood (e.g., with anger in response to frustration or belittlement), an inability to cognitively label these mood changes may further increase levels of arousal, resulting in inappropriate responses or damaging overreactions. One high-functioning individual recently reported to us that when under stress she often felt "as though the lights were going out inside me" but had no way of identifying or understanding the negative emotions that were causing this feeling.

A recent quantitative study (Allen \& Hill, 2010) further investigated differences between autistic and typical adults in their use of language to describe their emotional reactions to music. All participants were screened for alexithymia using the self-report measures TAS-20 (Bagby, Parker, \& Taylor, 1994) and BVAQ (Vorst \& Bermond, 2001). Scores on these measures were significantly higher for the ASD group than for the control group. The musical stimuli used in the experiment were previously piloted on a control group and expressed happiness, sadness and fear. A list of the 14 most common musical descriptor items (drawn from a pilot study with typical controls) were combined with an equal number of the words that had been used by the highfunctioning autistic adults in the qualitative study (Allen et al., 2009) to describe their typical reactions to music. Participants were asked to tick any of the 28 words that described their emotional responses to the musical passages they heard. It was emphasized that the emotion(s) checked must be one(s) evoked in them, rather than being simple descriptions of the music. 
Two findings emerged from this study. First, consistent with a predicted effect resulting from alexithymia, the autism group used significantly fewer words overall to describe their feelings in response to the music than the control group. However, the second result contradicted our expectations. There was no clear tendency for the autism group to prefer words describing internal arousal states to more externally focused words such as "hopeful," "wistful," and "sad." One interpretation of this finding is that people with autism are able to understand and use a wider range of emotion words when they are specifically cued.

\section{The Induction of Emotion by Music (1): Levinson's (2006) "Persona" Theory and Theories of Empathy}

Before considering interventions aimed at remediating alexithymia using music, it is necessary to briefly examine the extensive literature (see e.g., Juslin \& Sloboda, 2001) involving the debate between psychologists, musicologists, and philosophers of music as to how, and even whether, music can induce genuine emotions. Despite numerous studies claiming to demonstrate that music induces changes in affective states, heated exchanges over the issue of whether or not these changes can legitimately be classified as "emotions" continue to rage. Philosophers of music tend to emphasize the reality of the aesthetic as opposed to the emotional impact of music. Without becoming too deeply involved in this discussion, it has occurred to us that linking the issue to an active research area in another discipline-whose connection with it appears to have been overlookedmay serve to reconcile these polarized positions and increase our understanding of the problem.

A distinguished philosopher of music, Jerrold Levinson, has suggested (Levinson, 2006) that we perceive emotions in music by imagining the existence of a musical "persona" through which these emotions are expressed. Taking these ideas as our present basis for theorizing about music, it is plausible to suggest that we perceive emotion in this "persona" in the same way that we perceive emotions in people; in other words, using empathy. The simulation theory of empathy, as persuasively outlined by Goldman and Sripada (2005), proposes that we perceive the emotion in a person's face (to take only the visual modality) by simulating (and generating) the same emotion in ourselves at a subconscious level, a process likely involving the mirror neuron system. If we can generalize this theory to music, the distinction between emotions perceived in music and emotions evoked in the listener by music may be more apparent than real. If the simulation theory of empathy is correct, both interpretations may be true. We perceive the emotions in the musical persona and experience the emotions as part of the very process of perception. While there is as yet little firm evidence in favor of this idea, it is a fruitful area for further investigation.

\section{The Induction of Emotion by Music (2): "Supernormal Stimuli" and "Superexpressive Voices"}

Of relevance also to the debate on emotion and music is the work of Ramachandran and Hirstein (1999) on the neuroscience of art. While a number of professional sociologists and philosophers of aesthetics were hostile to what they perceived as the "reductionist" tone of the essay, the ideas outlined in the paper are entirely consistent with views outlined by Aldous Huxley in his book "Heaven and Hell" (2004), in which Huxley reflects on his experiences of taking the hallucinogenic drug mescaline. We particularly note similarities between Ramachandran and Hirstein's (1999) theory of the use of "supernormal stimuli" for artistic effect, and Huxley's description of an interior world of extreme sensations in the "mental antipodes" describing "praeternatural light, praeternatural intensity of coloring and praeternatural significance" (pp. 61-88). Huxley believed he had gained direct access to this internal world through the use of mescaline, but considered that artists through the ages had aimed at stimulating the same brain areas visually, by a process of abstraction and exaggeration.

The consistency between Huxley's (2004) ideas and the theory elaborated, in scientific detail, by Ramachandran and Hirstein (1999), are an encouraging sign that the current polarization between those who write about science and art is not inevitable. Importantly, such ideas may enable us to develop new ways of thinking about music. Taking for example the idea that musical instruments represent emotionally expressive sounds of human or animal origin ("superexpressive voices"; Juslin, 2001), we can draw parallels with visual art, in which certain characteristics of light, color, and form are exaggerated. In both music and visual art emotions may exemplify or represent simplified, exaggerated, and indeed purified versions of the emotions evoked in real life. Of course, everyday emotions are rarely if ever simple. In the same way that the colors of objects are always a mixture of spectral components of different wavelengths, emotions are grounded in the complexity of real life situations and comprise many different cognitive and physiological elements. By contrast, techniques of composition may allow 
not only the production or simulation of realistic emotions, but even the splitting of emotions into elemental or "monochromatic" parts and their representation and expression in this purified form. When perceived in all their simplicity, these emotions have a power and dramatic quality that is quite unique.

Whatever the nature of affective changes in response to music, and whether or not they are "genuine" emotions, it is the case that articulate adults regularly claim that certain passages of music arouse the same types of feelings that they experience in the broader social context. While the findings from different experimental studies may differ in details, they concur in finding that musical emotions overlap with everyday emotions without being co-extensive with them. Moreover, the existence of correlations between specific dramatic moods and specific musical characteristics in movie scores provides strong, albeit anecdotal, evidence that certain types of music affects individuals in similar ways.

\section{Self-Report Data on Emotions Induced by Music}

Returning to published experimental work on the nature of musical emotions, Zentner, Grandjean, and Scherer (2008) analyzed self-report data and observed first order factors identifiable with the emotions of joy, wonder, transcendence, nostalgia, tension, and sadness, among others. These overlap with, but do not map isomorphically onto, Ekman's categories of happiness, sadness, anger, fear, surprise, and disgust (Ekman \& Friesen, 1986). It seems to be generally agreed that anger, surprise, and disgust are difficult emotions to evoke musically, as well as being emotions that people seldom seek to experience via their planned listening experiences.

Zentner et al. (2008) also identified three secondorder factors, which they described as 'sublimity', 'vitality', and 'unease.' We consider that these factors might correspond to the three types of reactions that we noted in Allen et al. (2009) in our autism group. Here 'sublimity' would represent listeners' aesthetic reaction to music, 'vitality' would comprise the cluster of words synonymous with 'exhilaration,' 'excitement,' etc., that were used to describe positive reactions to music, and 'unease' would correspond to the 'tension/calmness' axis, representing the opposite pole to the desired state of calmness or relaxation that music was employed to induce. It may be that the typical listener's tendency to further subdivide Zentner's three second-order factors into specific musical emotions reflects confabulation, as outlined in the cognitive labelling theory of emotion (see e.g., Schachter \& Singer, 1962). Confabulation about the 'emotions' of the musical 'persona' (in Levinson's,
2006, sense) is more likely to happen in response to "superexpressive voices," and in the absence of other cues. People with autism are unlikely to engage in such confabulation.

In our currently unpublished work, we note that the words our typical control group chose to describe feelings or thoughts evoked by musical passages included a mixture of emotional language and imagery; for example: 'magical,' 'escaping,' 'thoughtful,' 'bright,' 'longing,' 'lively,' 'scared,' 'dramatic,' 'wistful,' and 'cheerful.' As far as we could ascertain by asking people to introspect about their responses to music, the emotions that they said they felt (ignoring the imagery that they used) covered a fairly broad range from positive to negative, and from high arousal levels (scared, lively) to low arousal levels (thoughtful, sad). Importantly, we also noted that there were considerable similarities between ways in which groups of adults, with and without autism, used music to achieve their aims in their everyday lives (Allen et al., 2009). On the basis of this finding we conjectured that the fundamental emotions experienced by our autism group might also be similar to those induced in the wider population, and that group differences in the use of musical descriptors might reflect the presence of alexithymia in the autism group. In other words, we would claim that the emotions experienced by the autistic group were the same as those experienced by the controls, but this was masked by the reduced ability of our autistic participants to describe them.

\section{Application to Clinical Interventions in Alexithymia: Developmental Origins}

On the principle that if one wishes to treat a condition one needs to understand its aetiology, our first step was to formulate a hypothesis about the developmental trajectory of alexithymia in autism. Since alexithymia reflects the absence of a typically observed behavior rather than the presence of an atypical behavior, it is important to ask how typically developing individuals avoid alexithymia: how do they learn to identify and label their own internal states? Conceptually, it is not obvious how humans arrive at a common language of terms that describe subjective and personal internal states. But it is appropriate to explore this question, since an understanding of the mechanism through which this ability is acquired in normal development may provide clues as to how the mechanism breaks down in autism spectrum disorders, and how such a deficit may therefore be remediated.

We hypothesize that one principal means through which connections between the affective and cognitive 
domains may be formed in normal development is via the link between basic emotions and culturally universal (Ekman \& Friesen, 1986) and possibly hard-wired facial expressions. While a very young infant will not have acquired internal language labels for its emotion states, these are nevertheless reflected in its facial expressions. Research has shown that during typical mother-baby interactions, a mother will often mimic or mirror her baby's facial expressions (Marcelli, Tourrette, Kasolter-Pere, \& Boinard, 2000). The typically developing infant attends to its mother's face and observes her expressions. We hypothesize that repeated associations in the infant's developing brain between its mother's facial expressions and the infant's own internal feeling states form the basis of emotion labelling ability.

We suggest that this pre-linguistic association forms the scaffolding upon which the child subsequently constructs post-linguistic words and concepts. These are no longer purely internal and private (its own feeling) but are also external and public (a facial expression and a set of verbal labels). This interpersonal process may be supported culturally. For example, the widely popular 'Mr. Men' books include characters whose facial expressions are used to introduce a relatively wide repertoire of linked behaviors. 'Mr. Grumpy' shows a range of typically churlish behaviors, whereas 'Mr. Happy' smiles a lot and is pleasant to other people. The infant already knows what emotion goes with a 'Mr. Happy' face: it is the emotion that it was experiencing when it saw its mother with that same smiling facial expression (mirroring that of the infant). The book (or other cultural influence) teaches the infant the name, and other correlated qualities, of happiness.

We do not claim that this mechanism is exclusive. It is likely that emotional expressiveness via the voice is also important, especially for blind infants. But it is plausible that associating an emotion with a facial expression does typically play a very significant role.

How would this explanation inform our understanding of alexithymia in autism? Research shows that social communicative cues are less salient for infants who are subsequently diagnosed with autism; for them familiar faces, in particular those of their mothers, are not salient (Dawson et al., 2002). If the infant seldom orients to its mother's face, and does not observe her mimicry of its expressions, links between its own internal emotional states and her facial expressions will not be formed. We suggest that the autistic infant's inability to benefit from such early bootstrapping experiences may, at least in part, account for the phenomenon of alexithymia in autism.

\section{Application to Clinical Interventions in Alexithymia: Systematic Induction of Emotion by Music}

We conjectured above that the fundamental music emotions that our autism group experienced might be similar to those experienced by typical listeners, and that group differences found in experimental results reflect alexithymia in our autism group. This conjecture suggested to us that music might be of value in remediating alexithymia in high-functioning adults with autism. More exactly, we speculated that it might be possible to develop a procedure based on the induction of specific feeling states in participants, using labelled items of music. The objective would be to use this effect to allow participants to learn an association between the emotions they experienced when listening to music, and the conventional names for those emotions. This would help participants to learn to distinguish their particular varieties of negative and positive emotions, by associating them with passages of music, so that when they experienced a feeling they could give it a music-related label. This would enable them to gain insights into their mental states, which would both reduce anxiety and enable them to function better socially.

In developing a treatment for alexithymia in adulthood, one is faced with the problem of finding a substitute for the developmental process that, in typically developing individuals, enables them to associate internal feeling states with external signs. Having missed the early opportunities to map the internal and external worlds, alternative methods are needed to remediate difficulties in adults with developmental alexithymia. One possibility might be to develop a system using a camera and computer to analyze the facial expressions of a person on the autism spectrum and feed back the results, effectively reconstructing the baby-mother mirroring system but in adulthood. A system along these lines is already being developed by Professor Rosalind Picard in the MIT Media Lab, and is being tested on college-aged ASD students with promising results (Picard, in press).

Given that Picard's interesting work has not yet been fully developed and evaluated, we think it is worth attempting an approach that complements this work, and also builds on known strengths in musical appreciation in autism. It is possible that future approaches might combine Picard's work with our musical approach. However, the approach we have adopted differs from that of Picard in one fundamental way. In her work, moods and facial expressions are linked, and mood drives expression: the internal world drives the external 
one. By contrast, our approach would link internal and external worlds by using stimuli from the external world as the driver: we propose to use an external stimulus to induce a mood.

\section{Application to Clinical Interventions in Alexithymia: Associative Learning of Music/Emotion Links}

Although the process that enables typical individuals to forge links between cognition and their internal feeling states is unitary, it can be divided into two components conceptually. When considering the case of autism it is fruitful to consider these two components separately. The first part of the link would consist of developing some cognitive hook or sign with which to associate a given feeling state. This sign might be part of a private language or it might, for example, in the case of synaesthesia, be a link with another modality. In this case a person might associate a particular mood with a shade of color. This color would be without associations or significance for anyone other than the synaesthete so the association would be both cognitive and private. The second link differs from the first in being culturally based, rather than intrapersonal. For example, when using the word "anger," the individual can be confident that others from his/her culture will associate it with a specific mood state.

The point of this distinction is that an intervention that facilitates only the first part of the process might still be of value in mitigating the effects of alexithymia. This would be the case even if the individual did not develop the ability to fully identify his/her own emotions in culturally universal terms. As noted above, Spinoza (as cited in Russell, 1961) claimed that "an emotion which is a passion ceases to be a passion as soon as we form a clear and distinct idea of it." He was concerned with the negative effect of "passions" and considered that it was worth aiming to cultivate the ability to form "clear and distinct ideas" of one's internal feelings as a way of overcoming these negative effects. If Spinoza was right in this, then it may not matter if the "clear and distinct idea" cannot be formulated in terms of a common language. In the case of our hypothetical example, the individual might identify their internal state as a "lemon yellow" mood, or as "the way I always feel when I hear Brahms's Piano Concerto." While this may be of little help in enabling the individual to deal with the social implications of alexithymia, it may reduce the associated sense of helplessness and anxiety caused by the disorder. This is one instance where a private language may be comparable in usefulness with a public one.

Such an approach would use associative learning between a musical item and a mood as the basic mechanism. Given that there is no evidence that associative learning is impaired in autism (at least in high-functioning adults), this basis appears to be empirically sound. In order to make this approach work, we would aim to ensure that a given set of musical items could reliably induce a given set of moods in our participants. In previous piloting studies and in published work (e.g., Heaton et al., 2008), we showed that children with autism reliably matched excerpts of classical music with visual depictions of mood states. We would draw upon this repertoire of music in our study, bearing in mind that systematic trialling of musical items might be necessary to establish the most effective repertoire for each participant-a selection that is likely to vary from one participant to another, if only because their musical tastes are certain to differ widely (see also, Allen et al., 2009).

Once we had established that our participants associated a particular musical excerpt with an external mood state, we would increase the salience of this association. Thus, we would teach our participants to associate the musical cues with their own internal moods and to formulate verbal descriptions of these moods. This would probably involve a period of trial and error learning by participants. For our participant who regularly felt the "lights going out," for example, this would involve listening to a series of excerpts until s/he found one that induced feelings similar to her current mood, and then labelling that mood by the corresponding item of music. We envision participants possibly having something like an iPhone with visible icons corresponding to a range of alternative musical items that they could play to themselves.

While our previous research suggests that such an approach will be fruitful, it is possible that some individuals may show highly idiosyncratic, pre-existing associations between internal mood states and musical excerpts. However, the ability to externally label an internal mood state may be beneficial even if it does not conform to conventional associations. If, for example, the mood state induced by Barber's Adagio was associated with smiling and pleasure rather than with sadness, we would still value the participant's ability to associate a particular state of mind as his/her "Barber's Adagio mood."

Diagrammatically, we would see the process as a series of learned associations like this: 


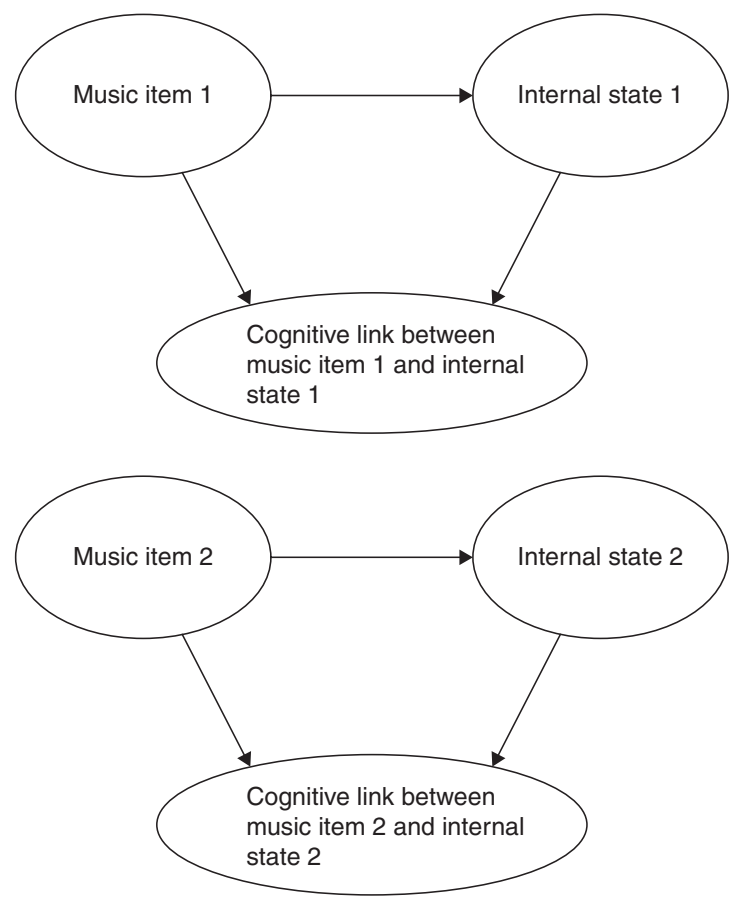

FIGURE 1. Diagrammatic representation of associative learning mechanism.

The case for the likely value of a music-based treatment for alexithymia in autism must consider the objection that the approach may be perceived as a form of music therapy that may be insufficiently scientific. For example, Kaplan and Steele (2005) note that music therapy evaluation studies often fail to include control groups, to detail objective measures of outcome, or to calculate statistical significance levels. Our response to this is that other studies (Whipple, 2004; Wigram \& Gold, 2006) have found evidence for its efficacy and limitations. The insufficiency of past studies should not preclude the future use of music in clinical contexts, provided that quantitative psychology methods are implemented in their evaluation.

To summarize, music appears to be a powerful tool for the induction of fundamental emotional states under controlled and safe conditions in autism. If it can be shown that participants' emotional states can be reliably induced by music, and they can link these with verbal descriptions, the clinical treatment of alexithymia will take a significant step forward.

\section{Author Note}

This work was supported in part by Goldsmiths, University of London.

Correspondence concerning this article should be addressed to Rory Allen, Department of Psychology, Goldsmiths, University of London, New Cross, London, United Kingdom SE14 6NW. E-MAIL: r.allen@gold.ac.uk

\section{References}

Allen, R., \& Hill, E. (2010). Finding the words for it: How alexithymia mediates ability to describe the emotional impact of music in autism. Manuscript in preparation.

Allen, R., Hill, E., \& Heaton, P. (2009). 'Hath charms to soothe ...' An exploratory study of how high-functioning adults with ASD experience music. Autism, 13, 21-41.

American Psychological Association (2000). Diagnostic and statistical manual of mental disorders (4th ed., text revision). Washington, DC: American Psychological Association.

Bagby, R. M., Parker, J. D. A., Taylor, G. J. (1994). The twenty-item Toronto alexithymia scale-I. Item selection and cross-validation of the factor structure. Journal of Psychosomatic Research, 38, 23-32.

Bailey, P. E., \& Henry, J. D. (2007). Alexithymia, somatization and negative affect in a community sample. Psychiatry Research, 150, 13-20.

BatT-Rawden, K., \& DeNora, T. (2005). Music and informal learning in everyday life. Music Education Research, 7, 289-304.
Berthoz, S., \& Hill, E. L. (2005). The validity of using selfreports to assess emotion regulation abilities in adults with autism spectrum disorder. European Psychiatry, 20, 291-298.

Bigand, E., Vieillard, S., Madurell, F., Marozeau, J., \& DACQUeT, A. (2005). Multidimensional scaling of emotional responses to music: The effect of musical expertise and of the duration of the excerpts. Cognition and Emotion, 19, 1113-1139.

Blum, K., Braverman, E. R., Holder, J. M., Lubar, J. F., Monastra, V. J., Miller, D., Et Al. (2000). Reward deficiency syndrome: A biogenetic model for the diagnosis and treatment of impulsive, addictive, and compulsive behaviors. Journal of Psychoactive Drugs, 32, 1-112.

Bonnel, A., Mottron, L., Peretz, I., Trudel, M., Gallun, E., \& Bonnel, A. M. (2003). Enhanced pitch sensitivity in individuals with autism: A signal detection analysis. Journal of Cognitive Neuroscience, 15, 226-235.

Bormann-Kischkel, C., Vilsmeier, M., \& Baude, B. (1995). The development of emotional concepts in autism. 
Journal of Child Psychology and Psychiatry and Allied Disciplines, 36, 1243-1259.

Bowler, D. (2007). Autism spectrum disorders. London: Wiley.

Capps, L., Yirmiya, N., \& Sigman, M. (1992). Understanding of simple and complex emotions in nonretarded-children with autism. Journal of Child Psychology and Psychiatry and Allied Disciplines, 33, 1169-1182.

Dawson, G., Carver, L., Meltzoff, A. N., Panagiotides, H., McPartland, J., \& Webb, S. J. (2002). Neural correlates of face and object recognition in young children with autism spectrum disorder, developmental delay, and typical development. Child Development, 73, 700-717.

DeNora, T. (2002). Crossing the divide: Feminist perspectives on gender and music. VI. The role of music in intimate culture: A case study. Feminism and Psychology, 12, 176-181.

Ekman, P., \& Friesen, W. V. (1986). A new pan-cultural facial expression of emotion. Motivation and Emotion, 10, 159-168.

Glaser, B. G., \& Strauss, A. L. (1967). The discovery of grounded theory: Strategies for qualitiative research. New York: Aldine.

Goldman, A. I., \& SRIPADA, C. S. (2005). Simulationist models of face-based emotion recognition. Cognition, 94, 193-213.

Happé, F., Ronald, A., \& Plomin, R. (2006). Time to give up on a single explanation for autism. Nature Neuroscience, 9, 1218-1220.

Heaton, P. (2003). Pitch memory, labelling and disembedding in autism. Journal of Child Psychology and Psychiatry and Allied Disciplines, 44, 543-551.

Heaton, P., Allen, R., Williams, K., Cummins, O., \& HAPPÉ, F. (2008). Do social and cognitive deficits curtail musical understanding? Evidence from autism and Down syndrome. British Journal of Developmental Psychology, 26, 171-182.

Heaton, P., Hermelin, B., \& Pring, L. (1998). Autism and pitch processing: A precursor for savant musical ability? Music Perception, 15, 291-305.

Heaton, P., Hermelin, B., \& Pring, L. (1999). Can children with autistic spectrum disorders perceive affect in music? An experimental investigation. Psychological Medicine, 29, 1405-1410.

Heaton, P., Pring, L., \& Hermelin, B. (1999). A pseudosavant: A case of exceptional musical splinter skills. Neurocase, 5, 503-509.

Hermelin, B., O’Connor, N., \& Lee, S. (1987). Musical inventiveness of 5 idiots-savants. Psychological Medicine, 17, 685-694.

Hill, E. L., Berthoz, S., \& Frith, U. (2004). Cognitive processing of own emotions in individuals with autistic spectrum disorder and their relatives. Journal of Autism and Developmental Disorders, 34, 229-235.
Hill, E. L., Sally, D., \& Frith, U. (2004). Does mentalising ability influence cooperative decision-making in a social dilemma? Introspective evidence from a study of adults with autism spectrum disorder. Journal of Consciousness Studies, 11, 144-161.

Huron, D. (2001). Is music an evolutionary adaptation? New York Academy of Sciences, 930, 43-61.

Huron, D. (2006). Sweet anticipation: Music and the psychology of expectation. Cambridge, MA: MIT Press.

Huxley, A. (2004). The doors of perception and heaven and hell. London: Vintage.

Jolliffe, T., \& BAron-Cohen, S. (1999). A test of central coherence theory: Linguistic processing in high-functioning adults with autism or Asperger syndrome: Is local coherence impaired? Cognition, 71, 149-185.

Juslin, P. N. (2001). Communicating emotion in music performance: A review and a theoretical framework. In P. N. Juslin \& J. A. Sloboda (Eds.), Music and emotion (pp. 309-37). Oxford: Oxford University Press.

Juslin, P. N., \& Sloboda, J. A., (Eds.) (2001), Music and emotion. Oxford: Oxford University Press.

Kaplan, R. S., \& Steele, A. L. (2005). An analysis of music therapy program goals and outcomes for clients with diagnoses on the autism spectrum. Journal of Music Therapy, 42, 2-19.

LAMONT, A. (2008). Young children's musical worlds: Musical engagement in 3.5-year-olds. Journal of Early Childhood Research, 6, 247-261.

Levinson, J. (2006). Contemplating art. Oxford: Oxford University Press.

Levitin, D. (2006). This is your brain on music. New York: Dutton. Marcelli, D., Tourrette, C., Kasolter-Pere, M. A., \& BoInARD, S. (2000). A depressed mother observes her child. A study of the search for behavioral signs which differentiate between depressed mothers and a control group of mothers in the neonatal period. Psychiatrie De L'Enfant, 43, 541-586.

Menon, V., \& Levitin, D. J. (2005). The rewards of music listening: Response and physiological connectivity of the mesolimbic system. Neuroimage, 28, 175-184.

Miller, L. K. (1999). The savant syndrome: Intellectual impairment and exceptional skill. Psychological Bulletin, 125, 31-46.

Mottron, L., Peretz, I., Belleville, S., \& Rouleau, N. (1999). Absolute pitch in autism: A case study. Neurocase, 5, 485-501.

Nettelbeck, T., \& Young, R. (1996). Intelligence and savant syndrome: Is the whole greater than the sum of the fragments? Intelligence, 22, 49-67.

North, A. C., Hargreaves, D. J., \& Hargreaves, J. J. (2004). Uses of music in everyday life. Music Perception, 22, 41-77. 
North, A. C., Hargreaves, D. J., \& O’Neill, S. A. (2000). The importance of music to adolescents. British Journal of Educational Psychology, 70, 255-272.

Peretz, I. (2001). Listen to the brain: A biological perspective on musical emotions. In P. N. Juslin \& J. A. Sloboda (Eds.), Music and emotion (pp. 105-134). Oxford: Oxford University Press.

PICARD, R. W. (in press). Future affective technology for autism and emotion communication. Philosophical Transactions of the Royal Society B: Biological Sciences.

QSR InTERnATIONAL (2006). NVivo 7 [Computer software]. Doncaster, Australia: QSR International.

Ramachandran, V. S., \& Hirstein, W. (1999). The science of art: A neurological theory of aesthetic experience. Journal of Consciousness Studies, 6, 15-51.

Russell, B. (1961). History of Western philosophy. London: Allen \& Unwin.

Sakurai, T., Ramoz, N., Reichert, J. G., Corwin, T. E., KryZAK, L., SMith, C. J., ET AL. (2006). Association analysis of the NrCAM gene in autism and in subsets of families with severe obsessive-compulsive or self-stimulatory behaviors. Psychiatric Genetics, 16, 251-257.

Salimpoor, V. N., Benovoy, M., Longo, G., Cooperstock, J. R., \& ZATORRE, R. J. (2009). The rewarding aspects of music listening are related to degree of emotional arousal. PLoS One, 4, e7487.
Schachter, S., \& Singer, J. (1962). Cognitive, social, and physiological determinants of emotional state. Psychological Review, 69, 379-399.

Sloboda, J. A., Hermelin, B., \& O’Connor, N. (1985). An exceptional musical memory. Music Perception, 3, 155-170.

THAYER, R. E. (1978). Toward a psychological theory of multidimensional activation (arousal). Motivation and Emotion, 2, 1-34.

Treffert, D. A. (1988). The idiot savant-A review of the syndrome. American Journal of Psychiatry, 145, 563-572.

Vorst, H. C. M., \& Bermond, B. (2001). Validity and reliability of the Bermond-Vorst alexithymia questionnaire. Personality and Individual Differences, 30, 413-434.

Whipple, J. (2004). Music in intervention for children and adolescents with autism: A meta-analysis. Journal of Music Therapy, 41, 90-106.

Wigram, T., \& Gold, C. (2006). Music therapy in the assessment and treatment of autistic spectrum disorder: Clinical application and research evidence. Child Care Health and Development, 32, 535-542.

Young, R. L., \& Nettelbeck, T. (1995). The abilities of a musical savant and his family. Journal of Autism and Developmental Disorders, 25, 231-248.

Zentner, M., Grandjean, D., \& Scherer, K. (2008). Emotions evoked by the sound of music: Characterization, classification, and measurement. Emotion, 8, 494-521. 
